\title{
The impact of energy-corrective measures at the design stage of construction projects
}

\author{
Oleg Korol ${ }^{1, *}$ \\ ${ }^{1}$ Moscow State University of Civil Engineering, 26, Yaroslavskoe shosse, 129337, Moscow, Russia
}

\begin{abstract}
The rational energy consumption during the construction period is formed at the stage of organizational and technological design by a system of energy-correcting measures. The implementation of the complex of measures allows balancing energy consumption and ensuring a high-quality production process with all types of energy users, infrastructural elements of the construction site, and the organization of the operating mode of machines, mechanisms, and labor resources. The object of the study is a complex of developed energy-correcting measures in the organizational and technological design of construction projects. Research methods include multi-criteria analysis based on expert assessments applied to the developed set of energy-correcting measures for the main types of energy consumers in the organizational and technological modeling of the construction process. This analysis of fuel and energy resources consumption by enlarged consumer groups - machines, mechanisms, and equipment; technological processes and infrastructure of the construction site. Varying the time parameters of beginning of the construction works has a significant influence on the consumption of fuel and energy resources for certain groups of consumers. The results of scientific research are presented in the form of a variable complex of energy-correcting measures that allow to flexibly regulating energy consumption in the process of organizational and technological design of buildings.
\end{abstract}

\section{Introduction}

Different life cycle stages of the construction sites are characterized by different volumes or levels of energy consumption. The organizational and technological mechanisms are developed to control and regulate energy consumption during the construction and operation of buildings, and used that allow balancing the interests of all participants in the investment and construction process and ensure rational energy costs in the high-tech process of building production and providing a comfortable and safe living environment for further operation. The object of the study is a complex of developed energy-correcting measures in the organizational and technological design of construction projects.

Effective energy consumption on the construction stage in the process is considered during the organizational and technological design, in view of the variability of kinds and types of construction equipment, the seasonality of works, infrastructure engineering

\footnotetext{
${ }^{*}$ Corresponding author : mrkorol.oleg@gmail.com
} 
maintenance of the construction site, the mode of technological processes and organization of works. The development and implementation of a complex of energy-correcting measures ensures a reduction in energy consumption or achieve predetermined level in the construction process.

The relevance of this study is due to the fact that vectors of the scientific and technical policy in the energy saving determine the development and improvement of technological and organizational methods of construction based on the principles of rational energy consumption [2-9].

Analysis of energy consumption at the construction site and reserves of their reduction is at the center of scientific approaches and principles for the formation of an increase in the efficiency of energy saving measures in construction industry [10-13]. This is reflected in the research aimed at the development and improvement of the regulatory framework [14-19].

Competitive advantages in practice of organizational-technological design of various energy-correcting actions are caused by carrying out of researches for acceptance of the proved decisions on the basis of such methods, as the method of the analysis of hierarchies, etc. [20]. The aim of this study is to develop organizational and technological mechanisms for regulating energy consumption for construction objects, in order to achieve that, the following objectives are set and solved:

- The development of energy-correcting measures and assessment of results;

- The development of evaluation criteria for energy-correcting measures;

- Multi-criteria analysis of energy-correcting measures;

- The ranking of energy-correcting measures according to the degree of their importance for different types of energy consumers.

\section{Methods}

The construction site is characterized by the integration of various types of energy consumers. The main ones are machinery and equipment, technological processes, as well as infrastructure of the construction site.

Therefore, integrated schedule for the consumption of fuel and energy resources can be presented in the form of a diagram of the daily fuel consumption by all types of energy consumers in unified units of measurement ( $\mathrm{kg}$ of fuel equivalent), the general view is shown in Figure 1

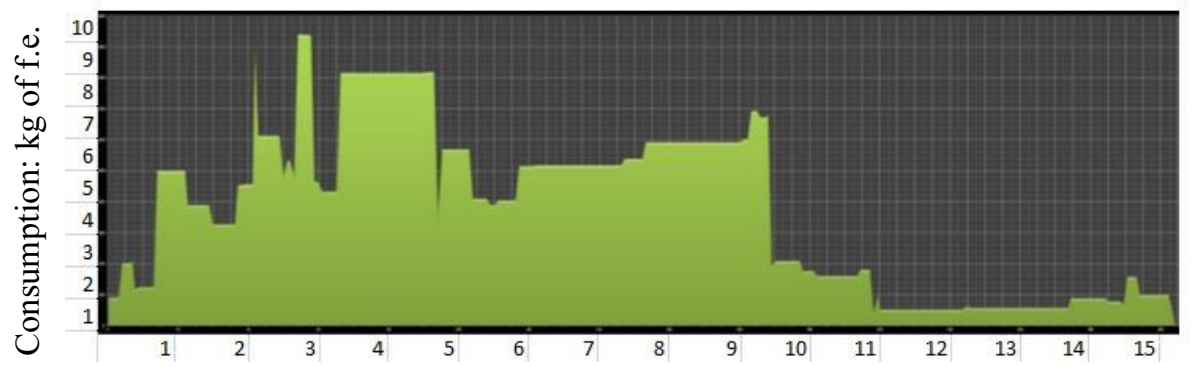

Days

Fig. 1. The general view of the daily fuel consumption schedule.

The calculation of fuel and energy resources consumption by different consumers occurs with the calendar factor to their hourly expenditure and the degree of employment during working hours. In general, the formula (1) for calculating the consumption of fuel and energy resources by various consumers is: 


$$
W_{\text {consumer }}=Q_{\text {hour }} * k * T_{\text {day }} * T_{\text {work }} * B,
$$

where $W_{\text {consumer }}$ - the consumption of the fuel and energy resources consumer, $Q_{\text {hour }}$ - the hourly consumption of fuel and energy resources by the consumer, $k$ - the calendar factor for the hourly expenditure of fuel and energy resources, $T_{\text {day }}$ - the duration of the working day, $T_{\text {work }}$ - the duration of the works, $B$ - the level of employment of fuel and energy resources consumers.

Modeling of energy and fuel resources consumption for monolithic housing facilities revealed that the variation in the timing of the construction (for the same duration of works) significantly affects the integral consumption of energy resources during the production of the construction site. Thus, calculations will decrease the overall consumption of energy resources by $27 \%$ at the start of work in April compared with the beginning of October (Figure 2).

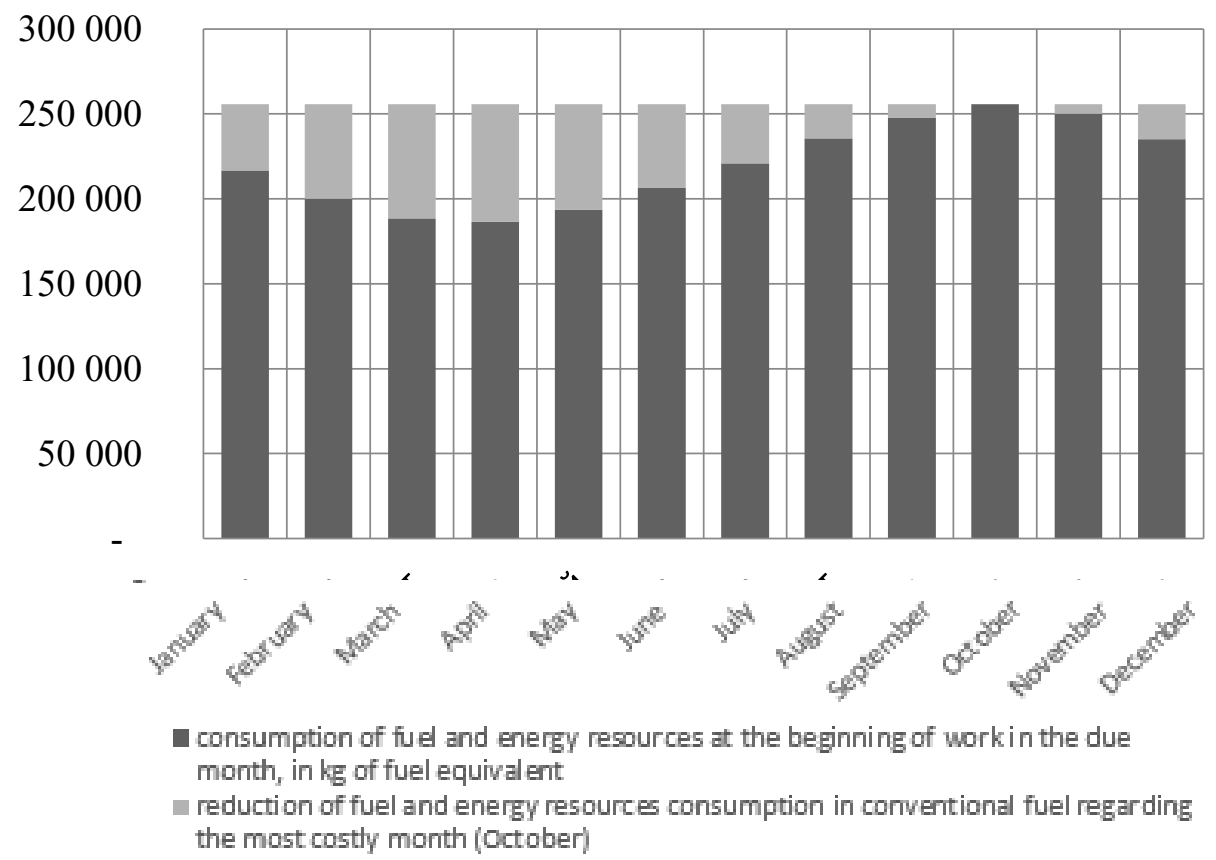

Fig. 2. Diagram of fuel and energy resources consumption changes depending on selection the month of beginning of the construction works.

\section{Results}

This analysis of fuel and energy resources consumption by enlarged consumer groups machines, mechanisms and equipment; technological processes and infrastructure of the construction site revealed significant differences between these groups. The significant expenditure of fuel and energy at the construction site comes from the operation of machinery, machinery and equipment. The cost of fuel and energy for the intensification of technological processes (for example, the temperature treatment of concrete, etc.) and the provision of engineering infrastructure in the amount, as a rule, do not exceed $20-25 \%$.

Varying the time parameters of beginning of the construction works also influences the consumption of fuel and energy resources for certain groups of consumers. For example, the consumption of fuel and energy resources by the group "Machines, machinery and 
equipment" at the beginning of construction in October is $13.7 \%$ higher than when the construction was postponed to April. The Figure 3 presents a comparative analysis of fuel and energy consumption for various enlarged consumer groups. The share of the fuel and energy resources consumption by the group "Machines, machinery and equipment" in the total consumption increases to $90 \%$ when beginning of the construction works in April. However, the analysis showed that this is due not to additional costs, but to a decrease in the share of the groups "Technological processes" and "Infrastructure of the construction site" from $17 \%$ and $9 \%$ (at beginning of the construction works in October) to $3 \%$ and $7 \%$ in total consumption fuel and energy resources for modeling construction of monolithic housing facilities in a predetermined range of the boundary conditions.
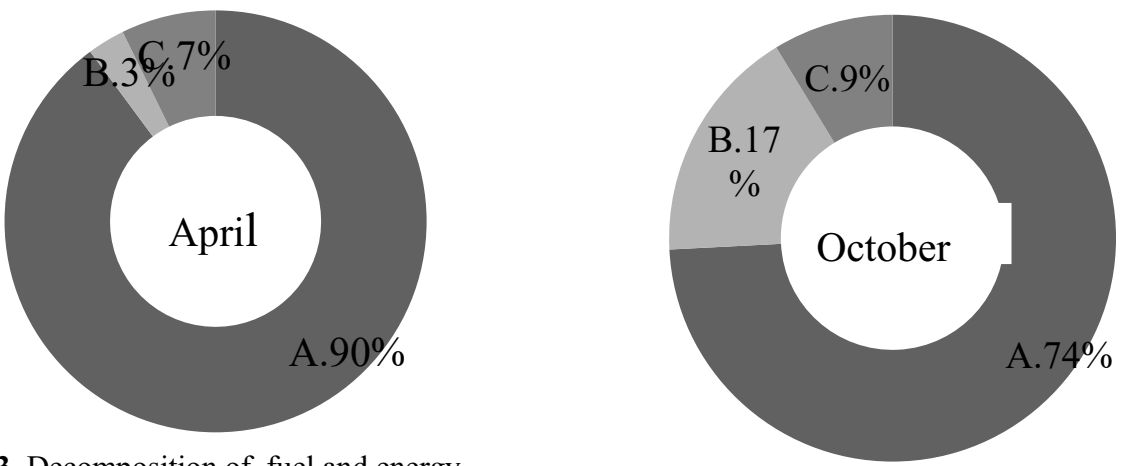

Fig. 3. Decomposition of fuel and energy resources consumption at the construction site by enlarged consumer groups with different dates of beginning of the construction works: A. Machines, mechanisms and equipment; B. Technological processes; C. Infrastructure of the construction site.

Decomposition of mechanized works (for example, the construction of monolithic housing facilities) made it possible to establish that at the beginning of the construction works in October, the share of the fuel and energy resources flow to the group "Heating of concrete" increases from $2 \%$ to $16 \%$, compared to the beginning of work in April. At the same time, energy costs vary depending on the seasonality of the work. Furthermore, it increase 9.7 times from $4290 \mathrm{~kg}$ of fuel equivalent. at the beginning of work in April, up to $41473 \mathrm{~kg}$ of fuel equivalent at the beginning of work in October.
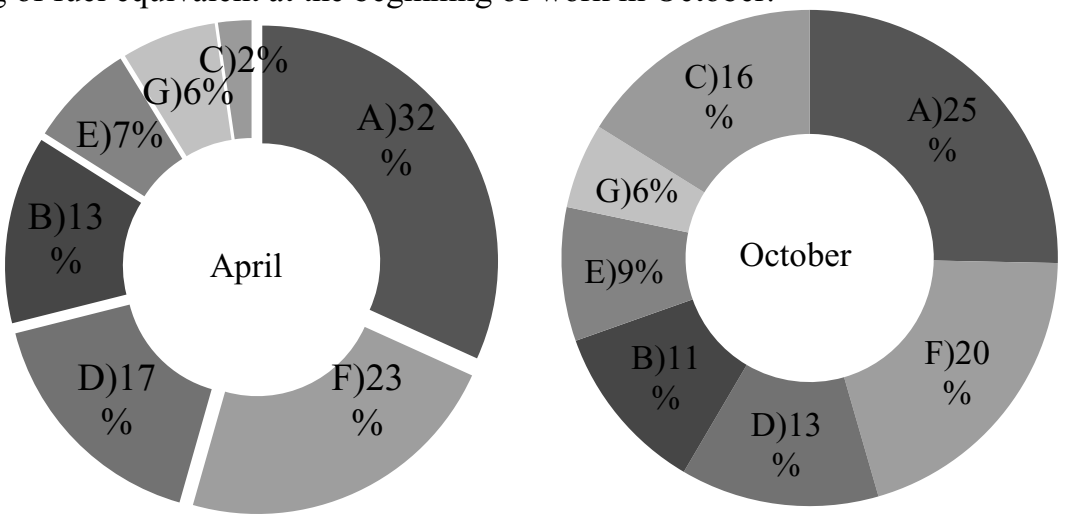

Fig. 4. Decomposition of mechanized works on the consumption of fuel and energy resources and their comparison in terms of the beginning of construction: A) Mechanized installation works; B) Mechanized excavation works; C) Heating of the concrete; D) Mechanized internal finishing works; E) Infrastructure of the construction site E) Mechanized concrete works; G) Auxiliary and preparatory works. 
As such, nomenclature of measures has developed, based on the analysis of the results of the study, that makes it possible to regulate energy consumption at the construction site in the production of works, the effectiveness of which is further evaluated by an expert method, based on the results of the multi-criteria analysis. These measures include the following:

- selection of the types and kinds of construction machines, machinery and equipment, in view of the minimization of work idle and under incomplete load (M1);

- calendaring, in view of the seasonality of work affecting the consumption of fuel and energy resources (fuel and energy resources) in different climatic conditions (M2);

- selection of temporary buildings and structures with high thermal protection characteristics (M3);

- selection of rational modes of technological processes with the least energy costs while ensuring the quality of quality of construction and installation works and intensification of technological processes (M4);

- development of the construction plan, in view of the minimization of the fuel and energy resources consumption for the engineering support of the construction site (M5);

- the rational organization of work on the appointment of shifts, the number of workers (in the most busy shift, including lighting works) (M6).

Multi-criteria analysis was performed to assess energy-corrective measures at the stage of organizational and technological design in terms of the most rational reduction of energy consumption at the construction site. The following were chosen as the main criteria:

$\mathrm{C}_{1}$ - versatility for all types of construction projects;

$\mathrm{C}_{2}$ - controllability in the automated mode;

$\mathrm{C}_{3}$ - possibility of application to various methods of construction;

$\mathrm{C}_{4}$ - adaptability to different climatic conditions;

$\mathrm{C}_{5}$ - the need for additional resource support.

Use the paired comparisons matrix is one of the most common methods of determining the weights of the criteria and evaluation the results [19]. When using this method, the results are compared among themselves in terms of their significance and are represented in the form of a priority vector, which is considered as a selection of "importance" factors of each result.

\section{Discussion}

At the first stage, a scale of priorities is established for the relative importance of each measure. The preferred combination of measures is expertly generated and reflected by one comparative number that is entered in the matrix. When filling the matrix of paired comparisons, the elements above the diagonal of the matrix are determined. The elements below the diagonal are calculated from the condition $\Omega \mathrm{ij}=1 / \Omega \mathrm{ji}$.

The ranking of energy-correcting measures according to the degree of their importance for different types of energy consumers in construction industry is performed (Table 1).

Table 1. Ranking of energy-correcting measures at the stage of organizational and technological design.

\begin{tabular}{|c|c|c|}
\hline \multicolumn{2}{|c|}{ Energy-corrective measures } & Rank of Importance \\
\hline $\mathrm{M}_{1}$ & $\begin{array}{c}\text { Selection of the types and kinds of construction machines, } \\
\text { machinery and equipment, in view of the minimization of work idle } \\
\text { and under incomplete load }\end{array}$ & 2 \\
\hline $\mathrm{M}_{2}$ & $\begin{array}{c}\text { Calendaring, in view of the seasonality of work affecting the } \\
\text { consumption of fuel and energy resources in different climatic } \\
\text { conditions }\end{array}$ & 1 \\
\hline
\end{tabular}




\begin{tabular}{|c|c|c|}
\hline$M_{3}$ & $\begin{array}{c}\text { Selection of temporary buildings and structures with high thermal } \\
\text { protection characteristics }\end{array}$ & 3 \\
\hline $\mathrm{M}_{4}$ & $\begin{array}{c}\text { Selection of rational modes of technological processes with the } \\
\text { least energy costs while ensuring the quality of quality of } \\
\text { construction and installation works and intensification of } \\
\text { technological processes }\end{array}$ & 5 \\
\hline $\mathrm{M}_{5}$ & $\begin{array}{c}\text { Development of the construction plan, in view of the minimization } \\
\text { of the fuel and energy resources consumption for the engineering } \\
\text { support of the construction site }\end{array}$ & 6 \\
\hline $\mathrm{M}_{6}$ & $\begin{array}{c}\text { The rational organization of work on the appointment of shifts, the } \\
\text { number of workers (in the most busy shift, including lighting } \\
\text { works) }\end{array}$ & 6 \\
\hline
\end{tabular}

The value of the indicator of importance of each energy-corrective measure by the formula (2):

$$
\begin{gathered}
\mathrm{K}_{\mathrm{mn}}=2(\mathrm{n}-\mathrm{i}+1) / \mathrm{n}(\mathrm{n}+1) 100 \\
\mathrm{~K}_{\mathrm{M} 1}=\frac{2(6-2+1)}{6(6+1)} 100=23.8 ; \mathrm{K}_{\mathrm{M} 2}=\frac{2(6-1+1)}{6(6+1)} 100=28.6 ; \\
\mathrm{K}_{\mathrm{M} 3}=\frac{2(6-4+1)}{6(6+1)} 100=14.29 ; \mathrm{K}_{\mathrm{M} 4}=\frac{2(6-3+1)}{6(6+1)} 100=19.05 ; \\
\mathrm{K}_{\mathrm{M} 5}=\frac{2(6-5+1)}{6(6+1)} 100=9.52 ; \mathrm{K}_{\mathrm{M} 6}=\frac{2(6-6+1)}{6(6+1)} 100=4.76
\end{gathered}
$$

The matrix of paired comparisons for the considered measures is created according to the expression (3):

$$
\Omega_{\mathrm{ij}}=\frac{\mathrm{K}_{\mathrm{i}}}{\mathrm{K}_{\mathrm{j}}} ;
$$

Table 2. Matrix of paired comparisons of energy-correcting measures.

\begin{tabular}{|c|c|c|c|c|c|}
\hline$\Omega_{1.1}=1$ & $\Omega_{1.2}=0.83$ & $\Omega_{1.3}=1.667$ & $\Omega_{1.4}=1.25$ & $\Omega_{1.5}=2.5$ & $\Omega_{1.6}=5$ \\
\hline$\Omega_{2.1}=1.2$ & $\Omega_{2.2}=1$ & $\Omega_{2.3}=2$ & $\Omega_{2.4}=1.5$ & $\Omega_{2.5}=3$ & $\Omega_{2.6}=6$ \\
\hline$\Omega_{3.1}=0.6$ & $\Omega_{3.2}=0.5$ & $\Omega_{3.3}=1$ & $\Omega_{3.4}=0.75$ & $\Omega_{3.5}=1.5$ & $\Omega_{3.6}=3$ \\
\hline$\Omega_{4.1}=0.8$ & $\Omega_{4.2}=0.667$ & $\Omega_{4.3}=1.33$ & $\Omega_{4.4}=1$ & $\Omega_{4.5}=2$ & $\Omega_{4.6}=4$ \\
\hline$\Omega_{5.1}=0.4$ & $\Omega_{5.2}=0.333$ & $\Omega_{5.3}=0.667$ & $\Omega_{5.4}=0.5$ & $\Omega_{5.5}=1$ & $\Omega_{5.6}=2$ \\
\hline$\Omega_{6.1}=0.2$ & $\Omega_{6.2}=0.167$ & $\Omega_{6.3}=0.333$ & $\Omega_{6.4}=0.25$ & $\Omega_{6.5}=0.5$ & $\Omega_{6.6}=1$ \\
\hline
\end{tabular}

Define the priorities vectors. For this, first multiply $n=6$ elements of each row and extract the root of the nth (6th) degree:

$$
\mathrm{Ni}=\left(\Omega_{1.1} \times \Omega_{1.2} \times \Omega_{1.3} \times \Omega_{1.4} \times \Omega_{1.5} \times \Omega_{1.6}\right)^{1 / 6}
$$

Then the obtained numbers are normalized according to the formula (5):

$$
\alpha \mathrm{i}=\mathrm{Ni} / \sum \mathrm{Ni}, \mathrm{i}=1,2 . . \mathrm{n}
$$

$$
\alpha_{\mathrm{M} 1}=\frac{1.67}{7.015}=0.238 ; \alpha_{\mathrm{M} 2}=\frac{2.004}{7.015}=0.286 ; \alpha_{\mathrm{M} 3}=\frac{1.002}{7.015}=0.143 \text {; }
$$




$$
\alpha_{\mathrm{M} 4}=\frac{1.336}{7.015}=0.19 ; \alpha_{\mathrm{M} 5}=\frac{0.668}{7.015}=0.095 ; \alpha_{\mathrm{M} 6}=\frac{0.334}{7.015}=0.048 .
$$

Then the ranking criteria for each energy-corrective measure is performed and the values of the importance indicator of each of the criteria considered are determined by the formula (2).

Table 3. Ranking of evaluation criteria for energy-correcting measures.

\begin{tabular}{|c|l|l|l|c|c|c|}
\hline \multirow{2}{*}{ Criteria } & \multicolumn{5}{|c|}{ M Ranks / Indicators of importance for measures } \\
\cline { 2 - 7 } & & & & & & \\
\hline $\mathrm{C}_{1}$ & $1 / 33.333$ & $1 / 3.333$ & $1 / 33.333$ & $1 / 33.333$ & $2 / 26.667$ & $1 / 33.333$ \\
\hline $\mathrm{C}_{2}$ & $4 / 13.333$ & $3 / 20$ & $3 / 20$ & $4 / 13.333$ & $3 / 20$ & $2 / 26.667$ \\
\hline $\mathrm{C}_{3}$ & $2 / 26.667$ & $2 / 26.667$ & $2 / 26.667$ & $5 / 6.667$ & $1 / 33.333$ & $5 / 6.667$ \\
\hline $\mathrm{C}_{4}$ & $3 / 20$ & $5 / 6.667$ & $5 / 6.667$ & $3 / 20$ & $5 / 6.667$ & $3 / 20$ \\
\hline $\mathrm{C}_{5}$ & $5 / 6.667$ & $4 / 13.333$ & $4 / 13.333$ & $2 / 26.667$ & $4 / 13.333$ & $4 / 13.333$ \\
\hline
\end{tabular}

Likewise, matrices of paired comparisons for the criteria $\mathrm{K} 1-\mathrm{K} 5$ are considered according to the expression ( 3 ) for all measures, priority vectors are determined and the obtained values are normalized according to formulas (4) and (5) (table 4).

Table 4. The matrix of paired comparisons of the criteria for measures and vectors of priorities.

\begin{tabular}{|c|c|c|c|c|c|c|c|c|}
\hline \multicolumn{7}{|c|}{ Matrices of paired comparisons } & $\begin{array}{l}\text { Vectors of } \\
\text { priorities }\end{array}$ & $\begin{array}{l}\text { Normaliza } \\
\text { tion }\end{array}$ \\
\hline \multicolumn{9}{|c|}{ Measure $\mathrm{M}_{1}$} \\
\hline$\Omega_{1.1}=1$ & $\Omega_{1.2}=2.5$ & \multicolumn{2}{|c|}{$\Omega_{1.3}=1.25$} & \multicolumn{2}{|c|}{$\Omega_{1.4}=1.667$} & $\Omega_{1.5}=5$ & 1.919 & 0.333 \\
\hline$\Omega_{2.1}=0.4$ & $\Omega_{2.2}=1$ & \multicolumn{2}{|c|}{$\Omega_{2.3}=0.5$} & \multicolumn{2}{|c|}{$\Omega_{2.4}=0.667$} & $\Omega_{2.5}=2$ & 0.768 & 0.133 \\
\hline$\Omega_{3.1}=0.8$ & $\Omega_{3.2}=2$ & \multicolumn{2}{|c|}{$\Omega_{3.3}=1$} & \multicolumn{2}{|c|}{$\Omega_{3.4}=1.333$} & $\Omega_{3.5}=4$ & 1.535 & 0.267 \\
\hline$\Omega_{4.1}=0.6$ & $\Omega_{4.2}=1.5$ & \multicolumn{2}{|c|}{$\Omega_{4.3}=0.75$} & \multicolumn{2}{|c|}{$\Omega_{4.4}=1$} & $\Omega_{4.5}=3$ & 1.152 & 0.2 \\
\hline$\Omega_{5.1}=0.2$ & $\Omega_{5.2}=0.5$ & \multicolumn{2}{|c|}{$\Omega_{5.3}=0.25$} & \multicolumn{2}{|c|}{$\Omega_{5.4}=0.333$} & $\Omega_{5.5}=1$ & 0.384 & 0.067 \\
\hline \multicolumn{9}{|c|}{ Measure $\mathrm{M}_{2}$} \\
\hline$\Omega_{1.1}=1$ & \multicolumn{2}{|c|}{$\Omega_{1.2}=1.667$} & \multicolumn{2}{|c|}{$\Omega_{1.3}=1.25$} & $\Omega_{1.4}=5$ & $\Omega_{1.5}=2.5$ & 1.919 & 0.333 \\
\hline$\Omega_{2.1}=0.6$ & \multicolumn{2}{|c|}{$\Omega_{2.2}=1$} & \multicolumn{2}{|c|}{$\Omega_{2.3}=0.75$} & $\Omega_{2.4}=3$ & $\Omega_{2.5}=1.5$ & 1.152 & 0.2 \\
\hline$\Omega_{3.1}=0.8$ & \multicolumn{2}{|c|}{$\Omega_{3.2}=1.333$} & \multicolumn{2}{|c|}{$\Omega_{3.3}=1$} & $\Omega_{3.4}=4$ & $\Omega_{3.5}=2$ & 1.535 & 0.267 \\
\hline$\Omega_{4.1}=0.2$ & \multicolumn{2}{|c|}{$\Omega_{4.2}=0.333$} & \multicolumn{2}{|c|}{$\Omega_{4.3}=0.25$} & $\Omega_{4.4}=1$ & $\Omega_{4.5}=0.5$ & 0.384 & 0.067 \\
\hline$\Omega_{5.1}=0.4$ & \multicolumn{2}{|c|}{$\Omega_{5.2}=0.667$} & \multicolumn{2}{|c|}{$\Omega_{5.3}=0.5$} & $\Omega_{5.4}=2$ & $\Omega_{5.5}=1$ & 0.768 & 0.133 \\
\hline \multicolumn{9}{|c|}{ Measure $\mathrm{M}_{3}$} \\
\hline$\Omega_{1.1}=1$ & $\Omega_{1.2}=4$ & \multicolumn{2}{|c|}{$\Omega_{1.3}=1.333$} & \multicolumn{2}{|c|}{$\Omega_{1.4}=0.8$} & $\Omega_{1.5}=2$ & 1.535 & 0.267 \\
\hline$\Omega_{2.1}=0.25$ & $\Omega_{2.2}=1$ & \multicolumn{2}{|c|}{$\Omega_{2.3}=0.333$} & \multicolumn{2}{|c|}{$\Omega_{2.4}=0.2$} & $\Omega_{2.5}=0.5$ & 0.384 & 0.067 \\
\hline$\Omega_{3.1}=0.75$ & $\Omega_{3.2}=3$ & \multicolumn{2}{|c|}{$\Omega_{3.3}=1$} & \multicolumn{2}{|c|}{$\Omega_{3.4}=0.6$} & $\Omega_{3.5}=1.5$ & 1.152 & 0.2 \\
\hline$\Omega_{4.1}=1.25$ & $\Omega_{4.2}=5$ & \multicolumn{2}{|c|}{$\Omega_{4.3}=1.667$} & \multicolumn{2}{|c|}{$\Omega_{4.4}=1$} & $\Omega_{4.5}=2.5$ & 1.919 & 0.333 \\
\hline$\Omega_{5.1}=0.5$ & $\Omega_{5.2}=2$ & \multicolumn{2}{|c|}{$\Omega_{5.3}=0.667$} & \multicolumn{2}{|c|}{$\Omega_{5.4}=0.4$} & $\Omega_{5.5}=1$ & 0.768 & 0.133 \\
\hline
\end{tabular}




\begin{tabular}{|c|c|c|c|c|c|c|}
\hline$\Omega_{1.1}=1$ & $\Omega_{1.2}=2.5$ & $\Omega_{1.3}=5$ & $\Omega_{1.4}=1.667$ & $\Omega_{1.5}=1.25$ & 1.919 & 0.333 \\
\hline$\Omega_{2.1}=0.4$ & $\Omega_{2.2}=1$ & $\Omega_{2.3}=2$ & $\Omega_{2.4}=0.667$ & $\Omega_{2.5}=0.5$ & 0.768 & 0.133 \\
\hline$\Omega_{3.1}=0.2$ & $\Omega_{3.2}=0.5$ & $\Omega_{3.3}=1$ & $\Omega_{3.4}=0.333$ & $\Omega_{3.5}=0.25$ & 0.384 & 0.067 \\
\hline$\Omega_{4.1}=0.6$ & $\Omega_{4.2}=1.5$ & $\Omega_{4.3}=3$ & $\Omega_{4.4}=1$ & $\Omega_{4.5}=0.75$ & 1.152 & 0.2 \\
\hline$\Omega_{5.1}=0.8$ & $\Omega_{5.2}=2$ & $\Omega_{5.3}=4$ & $\Omega_{5.4}=1.333$ & $\Omega_{5.5}=1$ & 1.535 & 0.267 \\
\hline \multicolumn{7}{|c|}{ Measure $\mathrm{M}_{5}$} \\
\hline$\Omega_{1.1}=1$ & $\Omega_{1.2}=1.333$ & $\Omega_{1.3}=0.8$ & $\Omega_{1.4}=4$ & $\Omega_{1.5}=2$ & 1.535 & 0.267 \\
\hline$\Omega_{2.1}=0.75$ & $\Omega_{2.2}=1$ & $\Omega_{2.3}=0.6$ & $\Omega_{2.4}=3$ & $\Omega_{2.5}=1.5$ & 1.152 & 0.2 \\
\hline$\Omega_{3.1}=1.25$ & $\Omega_{3.2}=1.667$ & $\Omega_{3.3}=1$ & $\Omega_{3.4}=2$ & $\Omega_{3.5}=5$ & 1.919 & 0.333 \\
\hline$\Omega_{4.1}=0.25$ & $\Omega_{4.2}=0.333$ & $\Omega_{4.3}=0.2$ & $\Omega_{4.4}=1$ & $\Omega_{4.5}=0.5$ & 0.384 & 0.067 \\
\hline$\Omega_{5.1}=0.5$ & $\Omega_{5.2}=0.667$ & $\Omega_{5.3}=0.4$ & $\Omega_{5.4}=2$ & $\Omega_{5.5}=1$ & 0.768 & 0.133 \\
\hline \multicolumn{7}{|c|}{$M_{2 a s u r e ~} \mathrm{M}_{6}$} \\
\hline$\Omega_{1.1}=1$ & $\Omega_{1.2}=1.25$ & $\Omega_{1.3}=5$ & $\Omega_{1.4}=1.667$ & $\Omega_{1.5}=2.5$ & 1.919 & 0.333 \\
\hline$\Omega_{2.1}=0.8$ & $\Omega_{2.2}=1$ & $\Omega_{2.3}=4$ & $\Omega_{2.4}=1.333$ & $\Omega_{2.5}=2$ & 1.535 & 0.267 \\
\hline$\Omega_{3.1}=0.2$ & $\Omega_{3.2}=0.25$ & $\Omega_{3.3}=1$ & $\Omega_{3.4}=0.333$ & $\Omega_{3.5}=0.5$ & 0.384 & 0.067 \\
\hline$\Omega_{4.1}=0.6$ & $\Omega_{4.2}=0.75$ & $\Omega_{4.3}=3$ & $\Omega_{4.4}=1$ & $\Omega_{4.5}=1.5$ & 1.152 & 0.2 \\
\hline$\Omega_{5.1}=0.4$ & $\Omega_{5.2}=0.5$ & $\Omega_{5.3}=2$ & $\Omega_{5.4}=0.667$ & $\Omega_{5.5}=1$ & 0.768 & 0.133 \\
\hline
\end{tabular}

The obtained data were used to determine the importance of criteria and energy-correcting measures at the stage of organizational and technological design. Normalized vectors of priority and its ranked criteria are used as benchmark data (Table 5).

Table 5. Benchmark data for assessing the significance of criteria at the stage of organizational and technological design.

\begin{tabular}{|c|c|c|c|c|c|c|}
\hline \multirow{2}{*}{\multicolumn{2}{|c|}{$\begin{array}{l}\text { Significance of } \\
\text { measures }\end{array}$}} & \multicolumn{5}{|c|}{ Significance of evaluation criteria } \\
\hline & & $\mathrm{C}_{1}$ & $\mathrm{C}_{2}$ & $\mathrm{C}_{3}$ & $\mathrm{C}_{4}$ & $\mathrm{C}_{5}$ \\
\hline $\mathrm{M}_{1}$ & $\alpha_{1}=0.238$ & $\alpha_{1} \mathrm{M}_{1}=0.333$ & $\alpha_{2} \mathrm{M}_{1}=0.133$ & $\alpha_{3} \mathrm{M}_{1}=0.267$ & $\alpha_{4} \mathrm{M}_{1}=0.2$ & $\begin{array}{c}\alpha_{5} \mathrm{M}_{1}= \\
0.067\end{array}$ \\
\hline $\mathrm{M}_{2}$ & $\alpha_{2}=0.286$ & $\alpha_{1} \mathrm{M}_{2}=0.333$ & $\alpha_{2} \mathrm{M}_{2}=0.2$ & $\alpha_{3} \mathrm{M}_{2}=0.267$ & $\begin{array}{c}\alpha_{4} \mathrm{M}_{2}= \\
0.067\end{array}$ & $\begin{array}{c}\alpha_{5} \mathrm{M}_{2}= \\
0.133\end{array}$ \\
\hline $\mathrm{M}_{3}$ & $\alpha_{3}=0.143$ & $\alpha_{1} M_{3}=0.267$ & $\alpha_{2} \mathrm{M}_{3}=0.067$ & $\alpha_{3} \mathrm{M}_{3}=0.2$ & $\begin{array}{c}\alpha_{4} \mathrm{M}_{3}= \\
0.333\end{array}$ & $\begin{array}{c}\alpha_{5} \mathrm{M}_{3}= \\
0.133\end{array}$ \\
\hline $\mathrm{M}_{4}$ & $\alpha_{4}=0.19$ & $\alpha_{1} M_{4}=0.333$ & $\alpha_{2} \mathrm{M}_{4}=0.133$ & $\alpha_{3} \mathrm{M}_{4}=0.067$ & $\alpha_{4} \mathrm{M}_{4}=0.2$ & $\begin{array}{c}\alpha_{5} \mathrm{M}_{4}= \\
0.267\end{array}$ \\
\hline $\mathrm{M}_{5}$ & $\alpha_{5}=0.095$ & $\alpha_{1} \mathrm{M}_{5}=0.267$ & $\alpha_{2} \mathrm{M}_{5}=0.2$ & $\alpha_{3} \mathrm{M}_{5}=0.333$ & $\begin{array}{c}\alpha_{4} \mathrm{M}_{5}= \\
0.067\end{array}$ & $\begin{array}{c}\alpha_{5} \mathrm{M}_{5}= \\
0.133\end{array}$ \\
\hline $\mathrm{M}_{6}$ & $\alpha_{6}=0.048$ & $\alpha_{1} \mathrm{M}_{6}=0.333$ & $\alpha_{2} \mathrm{M}_{6}=0.267$ & $\alpha_{3} \mathrm{M}_{6}=0.067$ & $\alpha_{4} \mathrm{M}_{6}=0.2$ & $\begin{array}{c}\alpha_{5} \mathrm{M}_{6}= \\
0.133\end{array}$ \\
\hline
\end{tabular}


The evaluation of the significance of the criteria for all the developed measures is carried out as follows:

Criterion C1: $0.238 \times 0.333+0.286 \times 0.333+0.143 \times 0.267+0.19 \times 0.333+0.095 \times$ $0.267+0.048 \times 0.333=0.317$

Criterion C2: $0.238 \times 0.133+0.286 \times 0.2+0.143 \times 0.067+0.19 \times 1.333+0.095 \times 0.2+$ $0.048 \times 0.267=0.155$;

Criterion C3: $0.238 \times 0.267+0.286 \times 0.267+0.143 \times 0.2+0.19 \times 0.067+0.095 \times 0.333+$ $0.048 \times 0.067=0.216$;

Criterion C4: $0.238 \times 0.2+0.286 \times 0.067+0.143 \times 0.333+0.19 \times 0.2+0.095 \times 0.067+$ $0.048 \times 0.2=0.168$;

Criterion C5: $0.238 \times 0.067+0.286 \times 0.133+0.143 \times 0.133+0.19 \times 0.267+0.095 \times$ $1.333+0.048 \times 1.333=0.142$.

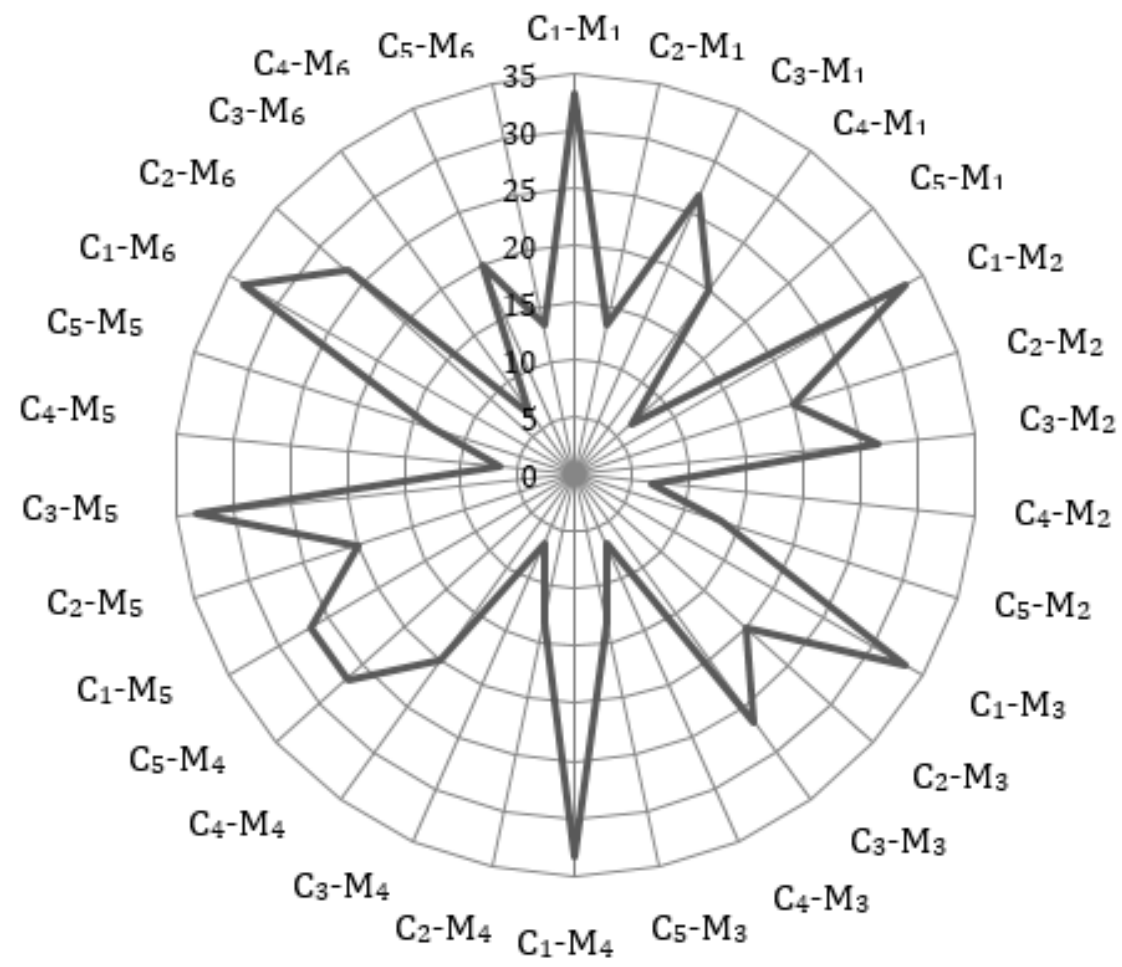

Fig. 5. The indicators of the importance of evaluation criteria for the stage of organizational and technological design.

It is difficult to compare the results of the research with the results of the research of other authors, since they expand the field of resource management in organizational and technological modeling and supplement it with energy resources $[3,4,16]$, in addition to traditional labor, time, material, etc.

At the same time, in the practice of research, authoritative scientists widely use methods of multicriteria analysis and expert assessments to develop rational organizational and technological solutions [17-22]. This approach makes it possible to effectively use the knowledge of the various aspects of building technologies accumulated by specialists for many years and different working conditions in suitable area of research. 


\section{Conclusion}

The development of a methodological base for organizational and technological modeling in the part of building diagrams for the consumption of energy resources during the erection of buildings was proposed:

1. Regulation of energy consumption in the construction of building objects can be achieved through organizational and technological modeling.

2. The construction of energy consumption diagrams in the period of the complete building construction cycle allows planning and flexibly adjusting the consumption of energy resources both for individual types of consumers and in general.

3. Varying the timing of the beginning and completion of construction in the construction of a diagram of energy consumption allows you to achieve a reduction in energy consumption in the construction process to $40 \%$.

4. Rational energy consumption at the construction site is regulated by a system of energy-correcting measures, taking into account their multi-criteria evaluation under given conditions.

In case of separately calculating, each measure is found that for most of the developed measures - the selection of types and kinds of construction machines, machinery and equipment, in view of the minimization of work idle and under incomplete load (M1); calendaring, considering the seasonality of works affecting the consumption of fuel and energy resources in different climatic conditions (M2); selection of temporary buildings and structures with high thermal protection characteristics (M3); selection of rational modes of technological processes with the least energy costs, while ensuring the quality of construction and intensification of technological processes (M4); the rational organization of work on the appointment of shifts, the number of workers (in the most busy shift, including lighting works) (M6), the first criterion $\mathrm{C} 1$ is also the most significant.

Modeling the change in the consumption of energy resources using energy-saving measures and their priority, established on the basis of multi-criteria evaluation, allows developing organizational and technological models based on the principle of rational provision of energy resources in the process of construction production.

\section{References}

1. G.I. Abdullayev, V.Z. Velichkin, T.N. Soldatenko, Magazine of Civil Engineering 3, 4350 (2013)

2. P.G. Grabovyi, E.A. Gusakova, A.M. Krygina, Real Estate: Economics, Management 2, 14-19 (2013)

3. M. Keshavarz Ghorabaee, M. Amiri, E.K. Zavadskas, Z. Turskis, J.A. Antucheviciene, Computers and Industrial Engineering 112, 156-174 (2017)

4. K. Kianpour, A. Jusoh, A. Mardani, D. Streimikiene, F. Cavallaro, K.M. Nor, E.K. Zavadskas, Sustainability 9(9), 1657 (2017)

5. E.A. Korol, Real estate: economics, management 2, 32-35 (2013)

6. E.A. Korol, N.S. Shushunova, Scientific Review 7, 144-147 (2014)

7. E.A. Korol, N.S. Shushunova, Scientific Review 8, 42-45 (2015)

8. E.A. Korol, N.S. Shushunova, Construction and reconstruction 3(65), 114-118 (2016)

9. O.A. Korol, K.P. Grabovyi, Natural and Technical Sciences 11-12(78), 399-401 (2014)

10. O.A. Korol, Scientific Review 12, 327-329 (2015) 
11. K.E. Anatolevna, K.P. Borisovich, International Journal of Applied Engineering Research 10(23), 43456-43460 (2015)

12. E. Korol, N. Shushunova, World Multidisciplinary Civil Engineering-ArchitectureUrban Planning Symposium, WMCAUS 2016, 1820-1826 (2016)

13. E. Korol, N. Shushunova, Procedia Engineering 153, 287-291 (2016)

14. E. Korol, P. Kagan, T. Barabanova, Applied Mechanics and Materials 44, 738-739 (2015)

15. P.P. Oleinik, V.I. Brodsky, Industrial and civil construction 12, 30-32 (2012)

16. T. Saati Prinyatiye resheniy. Metod analiza iyerarkhiy (Radio and Communication, Moscow, 1993)

17. A. Krylovas, E.K. Zavadskas, N. Kosareva, S. Dadelo, International Journal of Information Technology \& Decision Making 13(6), 1119-1133 (2014)

18. B. Soylu, B. Akyol, Computers \& Industrial Engineering 69, 12-20 (2014)

19. S. Zeng, T. Baležentis, J. Chen, G. Luo, Informatica 24(3), 485-503 (2013)

20. P. Zhou, L. Fan, European Journal of Operational Research 182(3), 1488-1491 (2007)

21. S.V. Korniyenko, N.I. Vatin, A.S. Gorshkov, Magazine of Civil Engineering 64(4), 10 25 (2016)

22. S.V. Korniyenko, Applied Mechanics and Materials 618, 509-513 (2014) 